\title{
Simple decompression versus anterior submascular transposition of ulnar nerve in the Treatment of Cubital Tunnel Syndrome
}

\author{
Authors \\ Dr Mustafa Elsagair ${ }^{1,2}$, Dr Wisam Abuzaid ${ }^{1,2}$, Dr Alaa Wafa ${ }^{1,3}$ \\ Dr Mustafa Makhlouf ${ }^{1,2}$, Dr Abdul Salamel Sharif ${ }^{1,2}$ \\ ${ }^{1}$ Aljazeera Orthopedic Hospital \\ ${ }^{2}$ Misurata Medical Centre \\ ${ }^{3}$ Misurata Cancer Centre
}

\begin{abstract}
Background: Cubital tunnel syndrome (CuTS) is the second most common entrapment neuropathy in the upper limb, after the entrapment of the median nerve in CTS

In this study, we aim to evaluate clinical and functional results in patients with cubital tunnel syndrome who were treated with submascular anterior transposition vs simple decompression of the ulnar nerve.

Methods: The study included 25 patients that were surgically treated in the orthopedic department at Aljazeera orthopedic Hospital - Misurata - between February 2015 and December 2018. These patients were randomly distributed into two groups. In the first grouponly simple decompression was performed, while in the second group anterior submascular transposition was supplemented. All cases were followed for at least 3 months. using the Bishop Score to assess outcome. A total of 25 procedures were performed with a minimum of 3 months' post-operative follow-up. All cases were operated (Dr. Alsagair and Dr. Abozaid)

Results: In the simple decompression group, (average age 45 years), the average Bishop Score was 11 with an average time to recovery of 8 weeks. Good to excellent results were obtained in $90 \%$ and fair results in $10 \%$.

In the anterior transposition group (average age 45 years) the average Bishop Score was 10.2 with average time to recovery of 9 weeks Good to excellent results were obtained in $86 \%$ and fair results in $13 \%$.

Complications included subluxation of the ulnar nerve in two cases, one wound dehiscence and one postoperative hematoma.

Conclusion: These long-term results show that both surgical techniques have a good outcome. Thus, the less invasive simple decompression should be preferred.
\end{abstract}

\section{Introduction}

Cubital tunnel syndrome is the second most common compressive neuropathy of the peripheral nerves. It results from compression of the ulnar nerve along its course around the elbow.

Several predisposing factors can cause CuTS such as repetitive elbow flexion and extension, habitual leaning on the elbow, as a outcome of elbow trauma, osteoarthritis, and chronic valgus stress. However, it is idiopathic in $20 \%$ of cases.

Compression of the nerve may be due to increased contents within Osborne's canal, e.g. lipomaabnormal muscles, tumors or a decrease in size of the cubital tunnel, e.g. in valgus 
abnormalities, fractures or osteophyte formation. Cubital tunnel syndrome may also be associated with systemic conditions such as diabetes mellitus and rheumatoid arthritis.

The majority of cases, however, remain idiopathic. Neuropathy in CubTS is mostly due to change in the volume and the pressure of the cubital canal with flexion and extension.

The neuropathy of cubital tunnel syndrome stems from alterations in the volume and the pressure of the cubital tunnel due to flexion and extension exerted on the ulnar nerve. Elbow flexion results in traction and excursion of the ulnar nerve and increases intraneural pressure. Prolonged elbow flexion gives rise to neuropathy and demyelination, commonly found in the bulbous swelling proximal to the nerve entry into the cubital tunnel

At the elbow, there are five anatomical regions where in ulnar nerve may be compressed: the arcade of Struthers, the proximal epitrochlear region, the epitrochlear-olecranon channel, the fibrous arch between the humeral and ulnar portions of the flexor carpi ulnaris, known as Osborne's arcade, and the vertical fibrous septum that stems from the ulna and separates the ulnar nerve and the ulnar part of the flexor carpi ulnaris from the flexor pronator muscles supplied by the median nerve.

Initial treatment of acute and subacute neuropathy is conservative. Conservative treatment should be tried for at least three months before surgical intervention, because symptoms may resolve in up to $50 \%$ of cases. Surgical decompression of the ulnar nerve is necessary for patients with unsuccessful conservative treatment, progressive ulnar nerve dysfunction or axonal damage in both sensory and motor conduction studies

The current surgical techniques for the treatment of cubital tunnel syndrome include simple decompression, medial epicondylectomy and anterior transposition of the ulnar nerve.

There is still no universal consent on the best surgical treatment and technique for CuTS. There are three frequently used surgical treatments and there are proponents for use of each treatment. First type of surgical treatment is simple decompression, by either open or endoscopic release of the Osborne's band. This is reserved for mild cases, with fresh onset of symptoms and mild sensory changes on the nerve studies, anterior transposition (subcutaneous, intramuscular or submuscular), medial epicondylectomy

\section{Materials and Methods}

This prospective study was conducted at the Orthopedic department, in Aljazeera orthopedic Hospital - Misurata -Libya , from February 2015 till December 2018.

Patients were divided into two groups according to surgical technique. Group 1 comprised 10 patients (3 males, 7 females; 6 right hands, 4 left hands; mean age, 45 years; range, 30-60 years) who underwent simple decompression of the ulnar nerve, where as Group 2 comprised 15 patients ( 7 males, 8 females; 9 right hands, 7 left hands; mean age, 45 years; range, 30-60 years) who underwent anterior intramuscular transposition of the ulnar nerve. All surgical procedures were performed by the same surgeons (Dr Alsagair and Dr Abozaid)

Tab 1 Age and Sex distribution between both groups

\begin{tabular}{|l|c|c|}
\hline & $\begin{array}{c}\text { Simple } \\
\text { transposition }\end{array}$ & $\begin{array}{c}\text { Anterior sub muscular } \\
\text { decompression }\end{array}$ \\
\hline Total & 10 & 15 \\
\hline Male & 3 & 7 \\
\hline Female & 7 & 8 \\
\hline Average age & 45 & 45 \\
\hline
\end{tabular}




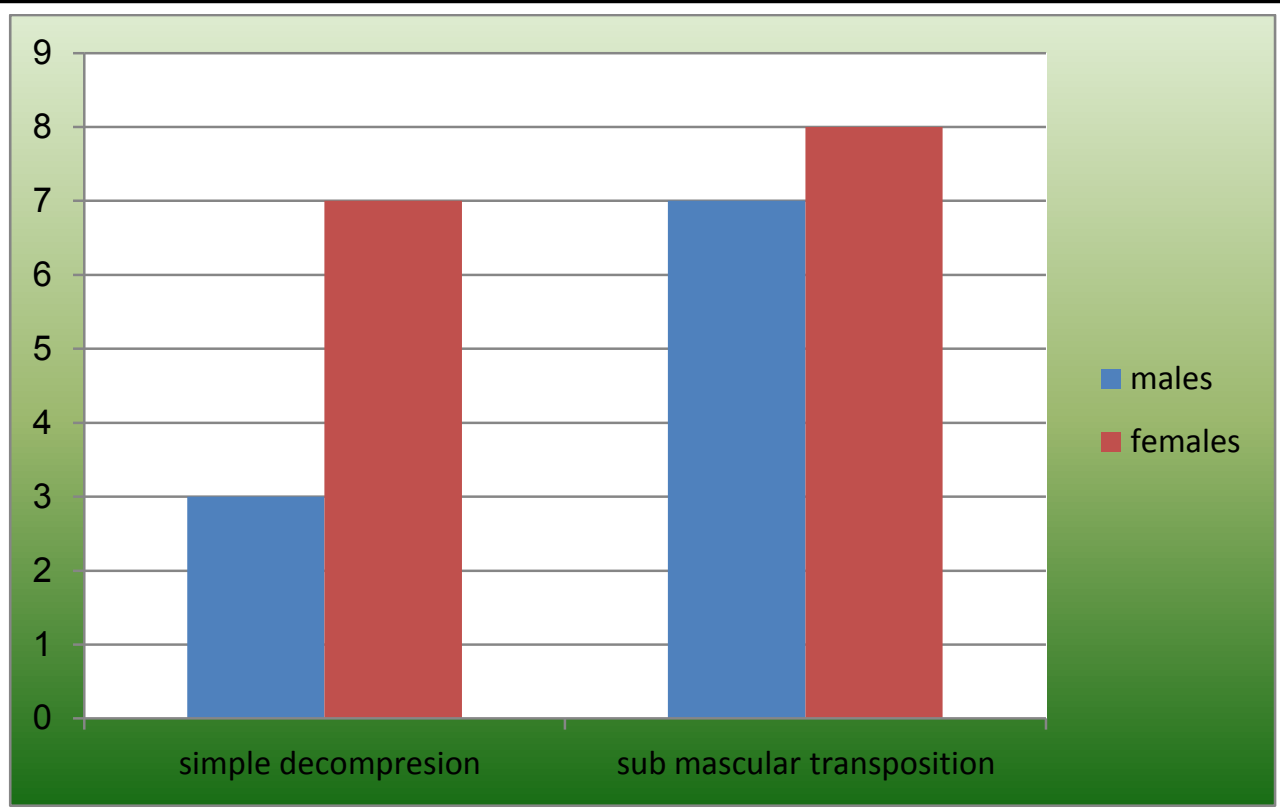

Fig 1 Sex distribution between both groups

\begin{tabular}{|c|c|}
\hline \multicolumn{2}{|l|}{ 1. Satisfaction } \\
\hline Satisfied & 2 \\
\hline Satisfied with reservation & 1 \\
\hline Dissatisfied & 0 \\
\hline \multicolumn{2}{|l|}{ 2. Improvement } \\
\hline Better & 2 \\
\hline Unchanged & 1 \\
\hline Worse & 0 \\
\hline \multicolumn{2}{|l|}{ 3. Severity of residual symptoms } \\
\hline Asymptomatic & 3 \\
\hline Mild & 2 \\
\hline Moderate & 1 \\
\hline Severe & 0 \\
\hline \multicolumn{2}{|l|}{ 4. Work status } \\
\hline Working or able to work at previous job & 1 \\
\hline Not working secondary to neuropathy & 0 \\
\hline \multicolumn{2}{|l|}{ 5. Leisure } \\
\hline Unlimited & 2 \\
\hline Limited 0 & 0 \\
\hline \multicolumn{2}{|l|}{ 6. Strength } \\
\hline Both grasp and pinch $>80 \%$ of normal side & 2 \\
\hline Either grasp or pinch (not both) $<80 \%$ & 1 \\
\hline Both grasp and pinch reduced $<80 \%$ & 0 \\
\hline \multicolumn{2}{|l|}{ 7. Sensibility ( 2 point discrimination) } \\
\hline Normal $<5 \mathrm{~mm}$ & 1 \\
\hline Abnormal $>5 \mathrm{~mm}$ & 0 \\
\hline Total & 13 \\
\hline
\end{tabular}

All patients were operated on by (Dr Alsagair - Dr Abozaid). The Bishop's score (Table 2) was used to evaluate outcome. A score of 10-13 was classed as excellent, 7-9 as good, 4-6 as fair and $0-3$ as poor. Included in the patient questionnaire was the time to recovery in weeks. 
Exclusion criteria were as follows: cervical radiculopathy, previous history of surgical intervention, angular elbow deformity, and neuropathies that had developed due to systemic diseases,

Cubital tunnel syndrome was diagnosed according to history and physical examination findings and was supported by electrodiagnostic test results. Particularly, loss of sensation and numbness on the ulnar side in the 4th and 5th fingers, medial elbow pain, weakness in intrinsic muscles, partial atrophy in the primary dorsal interosseous and hypothenar atrophy, and a positive Tinel's sign and two point differentiation test were important criteria for diagnosis. Cervical and elbow $\mathrm{x}$ rays were taken from all patients

Electrodiagnostic tests included nerve conduction studies and needle electromyography (EMG). Motor conduction velocity of less than $47 \mathrm{~m} / \mathrm{s}$ and sensory conduction velocity of less than $54 \mathrm{~m} / \mathrm{s}$ were considered abnormal. Pathologic EMG findings were abnormalities in fibrillation activity, reduced exposure and abnormalities in motor unit activation potential.

\section{Surgical Technique}

The procedures were performed under general anesthesia.

\section{Simple decompression of ulnar nerve}

In simple decompression, an incision was made along the course of the ulnar nerve, about $8-10 \mathrm{~cm}$ in length, from the tip of the olecranon and midway between the medial epicondyle.

This posterior incision was favored to avoid damage to medial anterior brachial cutaneous and medial brachial nerves. The medial inter muscular septum was cut and a localized decompression of the nerve was established by incising the osborn ligament and by incising the fascia holding the two heads of the flexor carpi ulnaris in order to open the tunnel between them. In addition, the cubital tunnel retinaculum was sharply divided in proximal-todistal direction

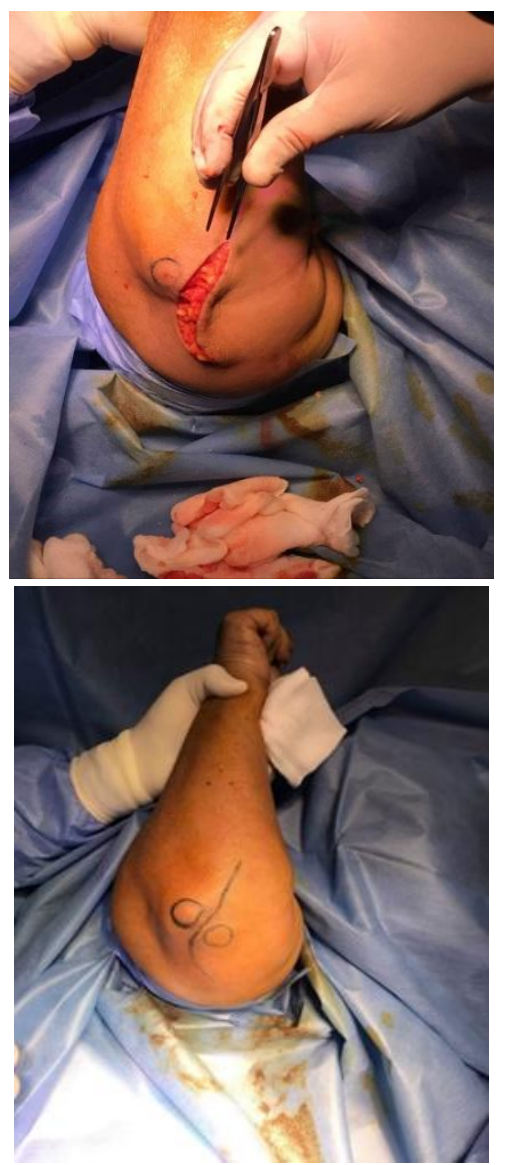

Fig 2-3. Site of incision in CubTS

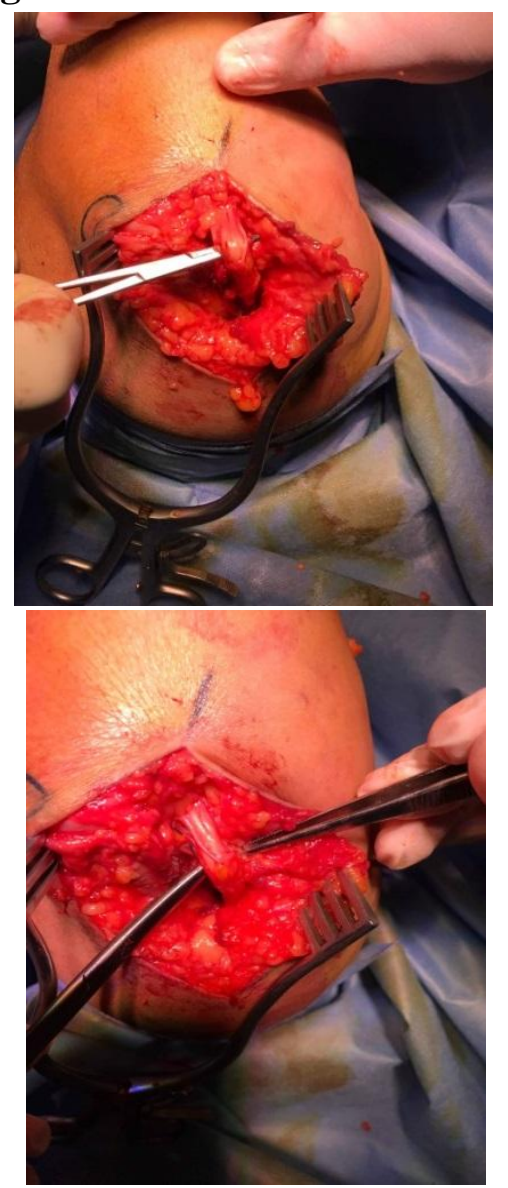

Fig 4-5. Simple decompression of ulnar nerve in CubTS 


\section{JMSCR Vol||08||Issue ||05||Page 503-511||May}

Anterior submuscular transposition of the ulnar nerve

In AST, a 10-cm curved skin incision is made posterior to the condylar groove of the humerus. Attention is taken to identify and protect the posterior branches of the medial antebrachial cutaneous nerve

The subcutaneous tissues are separated and the nerve is identified at the medial epicondyle immediately proximal to its entry into the cubital tunnel. The cubital tunnel retinaculum or arcuate ligament of Osborne is split and releases the nerve. Proximally, the nerve is followed to divide the intermuscular septum and the Struthers' arcade. Distally, the release is continued as the nerve passes through the two heads of the flexor carpi ulnaris muscle to ascertain complete decompression. The ulnar nerve is subsequently dissected from the ulnar groove bed and transposed to a position anterior to the medial epicondyle.

And the nerve was followed up to the two heads of the flexor carpi ulnaris. Ample division of the confluence of the two heads of the flexor carpi ulnaris and eventual section of the medial head was performed. The nerve was then isolated with soft loops and mobilized preserving the extrinsic vessels as accurately as possible. Then, splitting of the muscular pronator-flexor complex as a new bed for the ulnar nerve was performed. The nerve was transposed into the transected muscular complex near the median nerve and the muscular insertion was sutured above the nerve without traction. To ensure that there was no residual compression of the transposed nerve, the arm was flexed und extended. The superficial tissues were stitched in layers Following to surgery, the arm is kept in a long arm dressing with the elbow fixed at 90 degrees and forearm in mid-pronation for a 4 weeks period. Active range of motion starts at 4 weeks with interval splinting. At 6 weeks, a passive range of motion is started, together with a strengthening program.
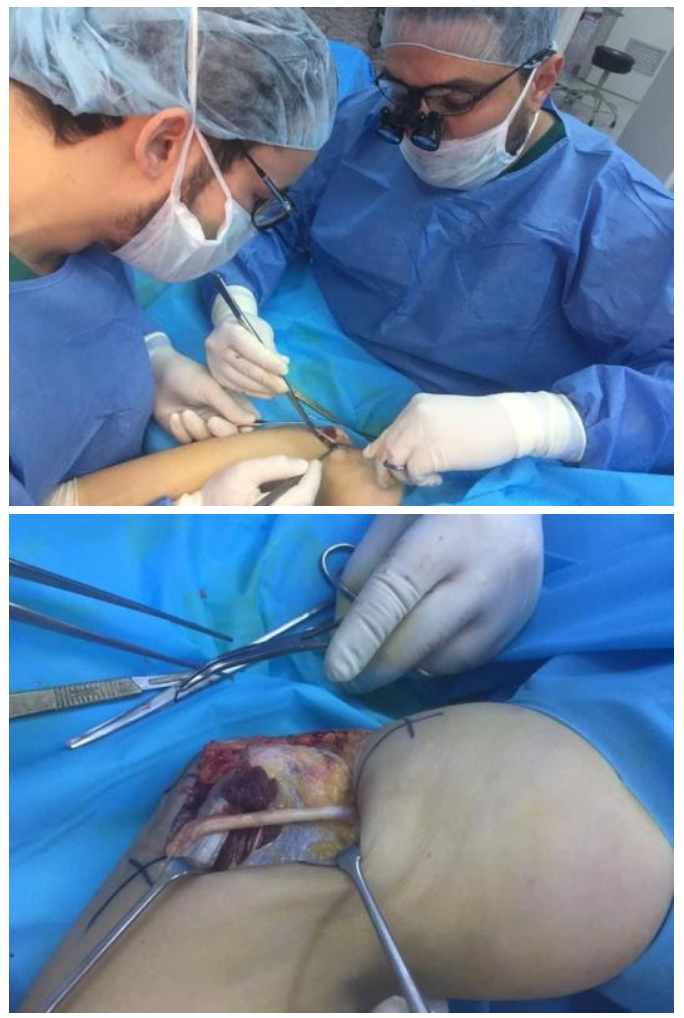

Fig 6-7 Release of ulnar nerve in Cub TS

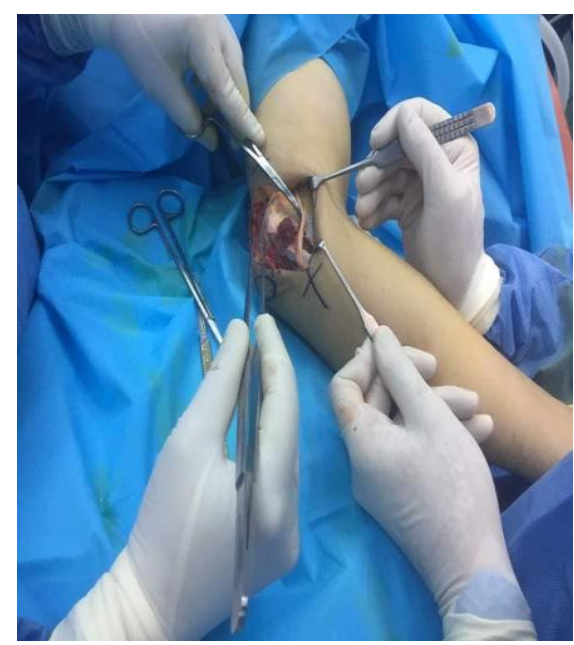

Fig 8 Submascular Position of ulnar nerve

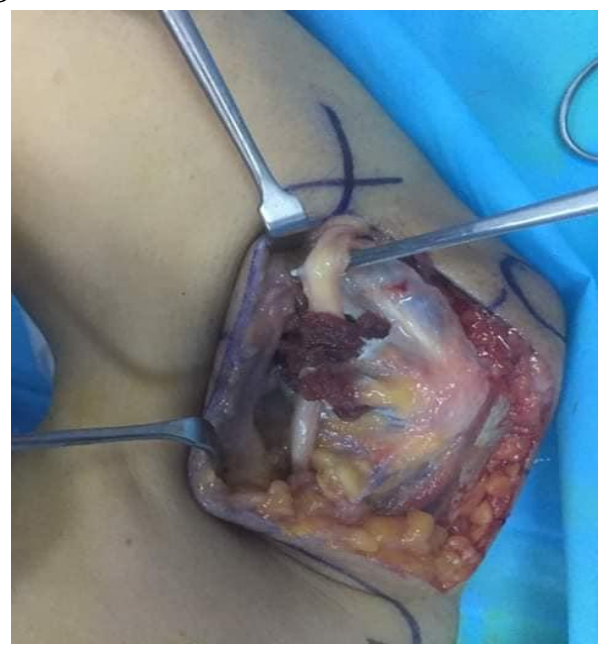

Fig 9 Anterior Transposition of ulnar nerve 


\section{JMSCR Vol||08||Issue||05||Page 503-511||May}

\section{Results}

Twenty-five patients underwent surgical decompression. The simple decompression group consisted of 10 cases and the anterior transposition group 15 cases. The minimum post-operative follow-up was 3 months and the longest was 24 months. In the simple decompression group there were $6(60 \%)$ excellent, $3(30 \%)$ good and $1(10 \%)$ fair in the post-operative Bishop's score (Table 2). There were no poor results.

In the anterior submuscular transposition group there were $10(66 \%)$ excellent, 3 (20\%) good, 2 $(13 \%)$ fair and no poor results. The average time to recovery was 8 weeks for the simple decompression group and 9 weeks for the transposition group. A significant number of patients, $8(80 \%)$ in the simple decompression group and $15(100 \%)$ in the transposition group, required $6-12$ weeks for recovery post-operatively. The time to recovery and the Bishop's score of the two groups was not statistically significant (Table 5). Both groups therefore had similar outcomes (Table 6).

Complications included one subluxation of ulnar nerve in the simple decompression group, and one postoperative hematoma and one wound dehiscence in the transposition group.

Table 4 Decompression versus transposition

\begin{tabular}{|l|l|}
\hline \multicolumn{2}{|l|}{ Decompression versus transposition } \\
$\begin{array}{l}\text { Simple } \\
\text { decompression }\end{array}$ & $\begin{array}{l}\text { Shorter operative time } \\
\text { Less invasive } \\
\text { Earlier post-operative mobilization } \\
\text { Bishop's score (average) =11 }\end{array}$ \\
\hline $\begin{array}{l}\text { Anterior intramuscular } \\
\text { transposition }\end{array}$ & $\begin{array}{l}\text { Longer operative time } \\
\text { Wider exposure } \\
\text { Delayed mobilization } \\
\text { Bishop's score (average) }=\mathbf{1 0 . 2}\end{array}$ \\
\hline
\end{tabular}

Tab 5 The time of recovery

\begin{tabular}{|l|c|c|}
\hline & $\begin{array}{c}\text { Simple } \\
\text { decompression }\end{array}$ & $\begin{array}{c}\text { Anterior submuscular } \\
\text { transposition }\end{array}$ \\
\hline After 3 wks & 2 & 0 \\
\hline After 6 wks & 4 & 6 \\
\hline After 9 wks & 2 & 2 \\
\hline After 12 wks & 2 & 2 \\
\hline
\end{tabular}

Tab 6 Summary of Bishop's score results for SD and AST

\begin{tabular}{|l|l|l|}
\hline & $\begin{array}{l}\text { Simple } \\
\text { decompression }\end{array}$ & $\begin{array}{l}\text { Anterior } \\
\text { muscular } \\
\text { transposition }\end{array}$ \\
\hline Excellent & 6 & 10 \\
\hline Good & 3 & 3 \\
\hline Fair & 1 & 2 \\
\hline average & 0 & 0 \\
\hline
\end{tabular}




\section{JMSCR Vol||08||Issue||05||Page 503-511||May}

Fig Simple decompression complication

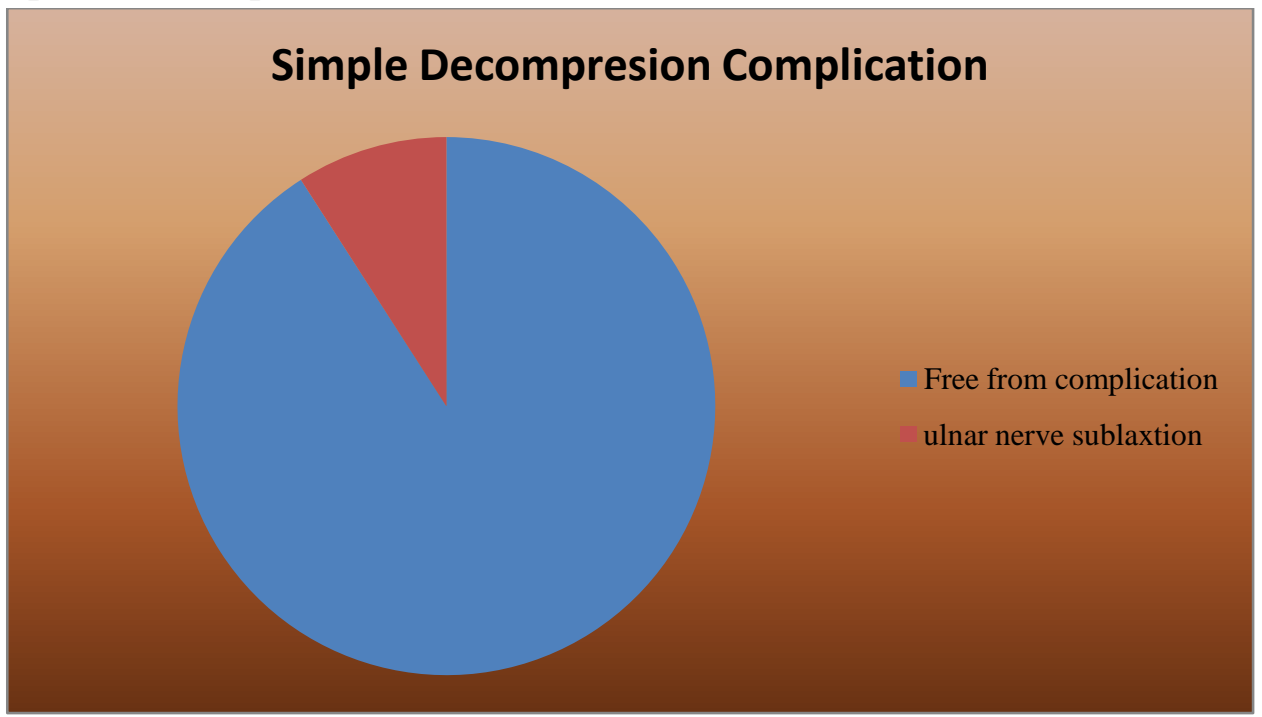

Fig Anterior submascular transposition complication

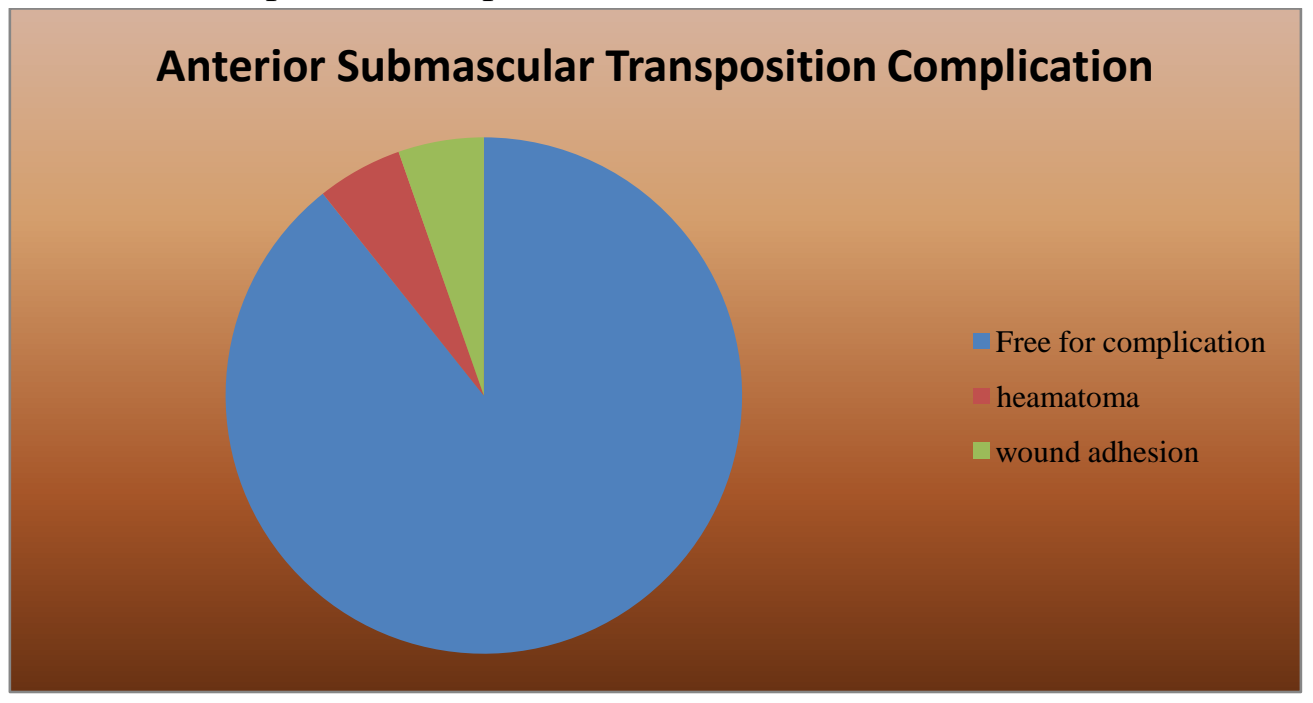

\section{Discussion}

Proponents of the different methods of ulnar nerve decompression in the treatment of cubital tunnel syndrome have reported variable effects. There are limited prospective randomized trials comparing simple decompression (SD) with anterior submascular Transposition of ulnar nerve (AST)

The mean age in our study is 45 years. This is similar to some other reports stating that younger age groups are more commonly affected. This could be recognized to the fact that these age groups are usually more active and more prone to injury and trauma. In our study, we found that females were more commonly affected than males $(60 \%)$, and this predominance can be attributed to the longer duration of elbow flexion during house actions, and their increased propensity to develop rheumatic illnesses. Thomsen et al is in agreement with the results.

Ogata et al. have shown in an experimental study that anterior transposition of the ulnar nerve is associated with a decrease in regional blood flow to the ulnar nerve for at least 72 hours after operation. Thus it is speculated if ischemia could contribute to formation of adhesions about the transposed nerve. In simple decompression, the ulnar nerve is left in its position without the risk of segmental ischemia caused by ligation of segmental vessels.

Biggs and Curtis et al published a randomized, prospective study comparing simple decompression with submuscular transposition in 44 patients. The postoperative outcome assessment was 1 month, 6 
months and 1 year after surgery. Each technique led to good results and these authors advocated simple decompression as the procedure with fewer complications

Gervasio et al. in 2006compared simple decompression with anterior submuscular transposition in Seventy patients. After follow-up of 48 months, neurological insufficiencies improved in each group and no statistically significant difference was seen-even in patients who showed signs of severe ulnar nerve compression before surgery. Both groups had good results in improvement of neurological deficits.

A comparison of the clinical outcomes in our study demonstrated a statistically significant difference in favor of simple decompression according to modified Bishop scoring. Ulnar nerve function improved in both groups compared with the preoperative period, and ulnar nerve paralysis was not seen in any of our cases. Scar incision was the most significant problem for patient satisfaction in the late post-operative time

\section{Conclusion}

The results of this study reveal that simple decompression and anterior submascular transposition of the ulnar nerve are almost equally effective in the treatment of CuTS, with a slightly better outcome with simple decompression. Simple decompression of the ulnar nerve in our study, because it is an effective and less invasive technique for CuTS.

\section{References}

1. Green, Hotchkiss, Pederson, Wolfe (2005) Green's operative hand surgery. (eds). Fifth edition, vol 1, 1024. Churchill Livingstone 2005.

2. Dörthe Keiner \& Michael R. Gaab \& Henry W. S. Schroeder (2009) Comparison of the longterm results of anterior transposition of the ulnar nerve or simple decompression in the treatment of cubital tunnel syndrome-a prospective study Acta Neurochir (2009) 151:311-316

3. Michael Ramsis Tawfik, Wael Mahmoud Khedr, Mahmoud Fathy Sakr (2017)
Comparative Study of Outcome of Simple Decompression Versus Anterior Transposition of Ulnar Nerve in the Treatment of Cubital Tunnel Syndrome National Journal of Health Sciences, 2017, 2, 52-56

4. Taskin Altay, Kamil Yamak (2018) Comparison of Simple Decompression and Anterior Subcutaneous Transposition of the Ulnar Nerve for the Treatment of Cubital Tunnel Syndrome Orr ttopediia Traumatologia Rehabilitacja MEDSPORTPRESS, 2018; 6(6); Vol. 20, 475-481

5. Dellon AL, Chang E, Coert JH, Campbell KR. (1994) Intraneural ulnar nerve pressure changes related to operative techniques for cubital tunnel decompression. J Hand Surg(Am) 1994;19A:923-30. 6. Contreras MG, Warner MA, Charboneau WJ, Cahill DR. (1998) Anatomy of the ulnar nerve at the elbow: potential relationship of acute ulnar neuropathy to gender differences. ClinAnat 1998; 11: 372-8.

7. Robertson C, Saratsiotis J.(2005) A review of compressive ulnar neuropathy at the elbow. $J$. Manipulative Physiol. Ther., 2005; 28(5): 345. DOI:10.1016/j.jmpt.2005.04.005

8. Greenwald D, Blum L, Adams D, Mercantonio C, Moffit M, Cooper B.(1996) Effective surgical treatment of cubital tunnel syndrome based on provocative clinical testing without electrodiagnostics. Plast. Reconstr. Surg., 2006; 117(5): 87-91.

9. Gellman H, Campion D.(1996) Modified in situ decompression of the ulnar nerve at the elbow. Hand Clin., 1996; 12(2): 421-33.

10. Huang J, Samadani U, Zager E.(2004) Ulnar nerve entrapment neuropathy at the elbow: simple decompression. Neurosurgery. 2004; 55(5): 1150-3. 11. Arle JE, Zager EL (2000) Surgical treatment of common entrapment neuropathies in the upper limbs. Muscle Nerve 23: 1160-1174

12. Kleinman W, Bishop A.(1989) Anterior intramuscular transposition of the ulnar nerve. $J$. Hand Surg. Am., 1989; 14(6): 972-9.

13. Nathan PA, Keniston RA, Meadows KD. (1995) Outcome study of ulnar nerve compression at the elbow treated with simple decompression and 
an early programme of physical therapy. J Hand Surg (Br) 1995;20B(5):62837.

14. Lascar T, Laulan J.(2000) Cubital tunnel syndrome: A retrospective review of 53 anterior subcutaneous transpositions. $J$ Hand Surg $\mathrm{Br}$ 2000;25B (5):453-6.

15. Ogata K, Manske PR, Lesker PA. (1985) The effect of surgical dissection on regional blood flow to the ulnar nerve in the cubital tunnel. Clin Orthop Rel Res 1985;193:195-

16. Filippi R, Farag $S$, Reisch $R$, Grunert $P$, Böcher-Schwarz H (2002) Cubital tunnel syndrome. Treatment by decompression without transposition of ulnar nerve. Minim Invas Neurosurg 45:164-168

17. Foster RJ, Edshage $\mathbf{S}$ (1981) Factors related to the outcome of surgically managed compressive ulnar neuropathy at the elbow level. J Hand Surg 6:181-192

18. Osborne G (1959) Ulnar neuritis. Postgrad Med J 35:392-396

19. Pasque CB, Rayan GM (1995) Anterior submuscular transposition of the ulnar nerve for cubital tunnel syndrome. J Hand Surg (Br) 20:447453

20. Pavelka M, Rhomberg M, Estermann D, Löscher WN, Piza-Katzer H (2004) Decompression without anterior transposition: an effective minimally invasive technique for cubital tunnel syndrome. Minim InvasNeurosurg 47:119123

21. Zlowodzki M, Chan S, Bhandari M Kalliainen L, Schubert W(2007) Anterior transposition compared with simple decompression for treatment of cubital tunnel syndrome. A metaanalysis of randomized, controlled trials. J Bone JtSurg Am 89:2591-2598

22. Liu Qq, Li R.(2016) Cubital tunnel syndrome treated with ulnar nerve simple decompression, anterior intramuscular or subcutaneous transposition: a parallel randomized controlled clinical trial. Clin Trials Orthop Disord2016; 1: 15-21.
23. Sean Boone BS, Richard H. Gelberman, (2015). The Management of Cubital Tunnel Syndrome J Hand Surg Am 2015; 40: 1897-904.

24. Ryan P Calfee, Palmer BA, Hughes TB. (2010) Cubital tunnel syndrome. J Hand Surg Am 2010; 35: 153-63.

25. Bacle G, Marteau E, Freslon M, et al. (2014) Cubital tunnel syndrome: comparative results of a multicenter study of 4 surgical techniques with a mean follow-up of 92 months. Orthop Traumatol Surg Res 2014; 100: 205-8.

26 Y Ramguthy, M Carides (2009) Cubital tunnel syndrome: Simple decompression versus decompression and anterior subcutaneous transposition - SA ORTHOPAEDIC JOURNAL Autumn 2009. 